\title{
Effect of Weaning Age on Stress-Related Behavior in Foals (Equus Caballus) by Abrupt - Group Weaning Method
}

\author{
Haixia Xiao', Tuohuti Ajide ${ }^{1}$, Li Zhang ${ }^{2 *}$, Guobin $\mathrm{Lu}^{2}$, Guoqing Shi ${ }^{3} \mathrm{Hai} \mathrm{Li}^{4}$ \\ ${ }^{1}$ Xinjiang Academy of Animal Sciences, Urumqi ,Xinjiang, China \\ ${ }^{2}$ Institute of Animal Science, Chinese Academy of Agricultural Sciences, Beijing, China \\ ${ }^{3}$ Xinjiang Academy of Agricltural and Reclamation Science, Shihezi , Xinjiang, China \\ ${ }^{4}$ Bureau of Animal Husbandry and Veterinary of Zhaosu county, Yili,Xinjiang, China
}

\begin{abstract}
Weaning is one of the most stressful periods in a foal's life. The traditional and most common weaning method is total and abrupt in China. The purpose of the research was to examine the stress-related behavioral response of foals and find the optimal weaning age by using abrupt and group weaning method. A total of 15 thoroughbred mare-foal pairs were divided into three groups $A$ (6-month foals, $n=5), B(7$-month foals, $n=5$ ) and $C$ (8-month foals, $n=5)$ according to the weaning age. These foals were observed for 3 days before weaning and 9 days after separation, and 15 behavioral patterns were compiled. All statistical analysis was performed by R2.14.2 (R Development Core Team). Comparing to pre-weaning, frequency of drinking, urination, fast-moving, aggression behaviors increased and the frequency of standing, lying and individual rolling behaviors decreased after separation for three groups. On the weaning day (Day 0), drinking, urination, social game, friend were most pronounced and standing, slow-moving, individual rolling was least pronounced in foals of group $A(p<0.05)$. Except for the same pronounce with group $A$, the frequency of fast-moving and individual nibbling were the highest in foals of group $B(0.53 \pm 0.49,0.77 \pm 0.15$ times $/ \mathrm{h}$, respectively) and the frequency of defecation, social kidding, individual nibbling behaviors were the highest in foals of group $C(0.38 \pm 0.11,1.75 \pm 0.87,0.71 \pm 0.08$ times $/ \mathrm{h}$, respectively) on the weaning day, whilst the frequency of slow-moving were strongly decreased in foals of group $B(10.88 \pm 0.69$ times $/ \mathrm{h})$ and the frequency of social suck were strongly decreased in foals of group $C(0.33 \pm 0.07$ times $/ \mathrm{h})$ on the weaning day. 8,12 and 13 behavior categories had changes in group A, group B and group $C$ during the observation phase. Weaning is associated with stress but 6 -month years old was least pronounced in foals by abrupt - group weaning method in China.
\end{abstract}

Keywords: Foal; Weaning age; Behavior; Abrupt and group weaning method

\section{Introduction}

To maximize the subsequent reproductive efficiency of the mares and allow for the marketing or specialized feeding of the foals, the artificial weaning is universally applied in horse production. The weaning period is a critical and particularly stressful phase in horse production, representing a major transition for foals from dependence to independence. It is well known that the weaning process is associated with potential psychological, physical and nutritional stressors that affect foal welfare [1-4]. The most important factors causing stress in this phase include separation from the mare which entails cessation of milk as the main nutritional source, changes in the social environment and often also the housing environment [4-6]. These situations may lead to increased vocalizing and increased general activity, weight loss, prolonged distress, poor welfare and economic loss $[7,8]$.

Many different weaning methods are utilized by mare owners and breeding farm managers, but regardless of the methods employed, stress-reduction at the time of weaning should be the primary concern [9]. The traditional and most common weaning method is total and abrupt weaning. To reduce weaning stress, studies in most livestock species focused on abrupt, gradual or two-stage weaning [9-18]. McCall suggested that foals weaned by partial weaning exhibited less stress than those weaned by abrupt separation [7]. Holland found that foals weaned in groups by gradually removing one mare at a time every second day were less stressed than foals of groups where all mares were removed at once [19]. Weaning by stepwise removal of the mares from pasture and leaving the foals in a familiar surrounding was a good weaning method to decrease the weaning stress [8]. Weaning in pairs appeared to be less stressful than weaning individually [20]. The paddock-reared weanling had improved welfare compared to individually stabled weanlings [21]. Similarly, Nicol noted that barn-weaned foals appeared more stressed than paddock-weaned foals [22]. Haley reported that weaning in two stages reduced the signs of behavioural distress compared with the traditional method of abrupt weaning in calves [16].
Studies in other livestock species suggest that generally, weaning at a younger rather than older age reduces welfare of the offspring. Fraser [23] reported that newly-weaned piglets were more active, aggressive, and belly-nosing. However little is known about the effect of age at weaning on the welfare of the foals. In the above-cited studies the majority of the horses $70 \%$ were weaned between ages of 4 and 6 month and $12 \%$ were more than 8 month at weaning [8].

The abrupt weaning is so wide used in China that to minimize the weaning stress and maximize the foal welfare, the purpose of this study was to examine the stress-related behavioural response of foals and find the optimal weaning age by using abrupt and group weaning method.

\section{Materials and Methods}

\section{Animals}

A total of 15 thoroughbred mare-foal pairs, including 9 colts and 6 fillies, participated in this experiment. All horses were kept at a Xinjiang Yili Zhaosu stud, China. Foals were between 6, 7 and 8 month of age when they were weaned. For the assessment of different weaning ages, the mares and their foals were divided into three groups A (6-month), B (7-month) and C (8-month) according to foal's age, which had 5 mare-foal pairs in each groups including 3 colts and 2 fillies.

*Corresponding author: Li Zhang, Institute of Animal Science, Chinese Academy of Agricultural Sciences, 100193, Beijing, China, Tel: +86-010-62818815; E-mail: zhangli@263.net

Received April 17, 2015; Accepted April 24, 2015; Published May 02, 2015

Citation: Xiao H, Zhang L, Tuohut A, Shi G, Li H (2015) Effect of Weaning Age on Stress-Related Behavior in Foals (Equus Caballus) by Abrupt - Group Weaning Method. J Phylogen Evolution Biol 3: 151. doi:10.4172/2329-9002.1000151

Copyright: (c) $2015 \mathrm{Xiao} \mathrm{H}$, et al. This is an open-access article distributed under the terms of the Creative Commons Attribution License, which permits unrestricted use, distribution, and reproduction in any medium, provided the original author and source are credited. 


\section{Experimental procedures and observations}

Mare-foal pairs were kept together as a group on the sports field during day time and kept in the stall at night time before weaning. Behaviors of mares and foals was observed by the video cameras. Observations were taken using the time sampling method with intervals of 5 minutes and record the frequency. Observations were taken for each group during 1-h bouts every other hour between 10:00 and 19:00. The foals were observed for 3 days before weaning and 9 days after separation, to compile an ethogram which includes ingestion, excretion, movement, social and individual behavioural patterns (Table 1).

On the day of weaning, all of mares and foals were led into a 200 $\mathrm{m}^{2}$ loose box for group-housing of foals. When all animals were inside the box, the mares were led out of the box and brought to boxes in a building located at a distance of about $200 \mathrm{~m}$ from the foals' boxes. After removing mares, behaviour of foals was observed 9 days via video cameras. A total of four cameras (one for each new weanling) were positioned such that the entire box was visible. 12V LED-Infraredprojectors (Videor Technical GmbH) were used to ensure night vision. The protocol for behaviour observations was the same for the video recordings as described for the live observations.

\section{Statistical analysis}

All statistical analysis was performed by R2.14.2 (R Development Core Team). Duncan's new multiple range test was utilized to compare difference with weaning age, weaning phase, gender, days, the significance level was set at $P<0.05$.

\section{Result}

\section{Behavioral observations from pre-weaning to post-weaning phase for group A (6-month foals)}

On the day of weaning (Day 0), the frequency of urination and social game behaviors were the highest $(0.50 \pm 0.17,0.92 \pm 0.09$ times/h, respectively) comparing to pre-weaning and post-weaning phase (Table 2, $P<0.05$ ), while the frequency of drinking and friend behavior patterns on the weaning day and post-weaning phase more significantly increased than pre-weaning $(P<0.05)$ and drinking and friend behavior frequencies attached the highest value $(1.58 \pm 0.25$ 和 $0.83 \pm 0.50$ times/h, respectively) on the weaning day. Contrarily, the frequency of standing, slow-moving and individual rolling behavior patterns on the weaning day and post-weaning phase more significantly decreased than pre-weaning $(P<0.05)$ and standing, slow-moving and individual rolling behavior frequencies attached the lest value $(4.59 \pm$ $4.59,9.75 \pm 0.08,0.00 \pm 0.00$ times/h, respectively) on the weaning day. The frequency of social suck on the weaning day and post-weaning phase was significantly lower with the pre-weaning, however the least frequency were $0.21 \pm 0.05$ times/h on the post-weaning phase. The time budget between pre-weaning, weaning day and post-weaning had no significant effect on the number of recordings of other 7 behavior categories (Table 2).

Differences behavior between pre-weaning, weaning day and postweaning phase for group A (6-month foals) (Mean \pm S.E)

Numbers with different letters within each behavior are significantly different $(P<0.05)$.

\section{Behavioral observations from pre-weaning to post-weaning phase for group B (7-month foals)}

In comparison with the pre-weaning and post-weaning phase, the frequency of urination, individual nibbling were strongly increased on the weaning day (Table $3, P<0.05$ ), and their frequencies were the highest on the weaning day $(0.34 \pm 0.05,0.77 \pm 0.15$ times $/ \mathrm{h}$, respectively). The drinking, fast-moving, social kidding, social biting and social suck behaviors on the weaning day and post-weaning phase more increased than these behaviors on the pre-weaning phase, moreover drinking, fast-moving and social suck behaviors got the highest values on the weaning day $(1.86 \pm 0.16,0.53 \pm 0.49,0.42 \pm$ 0.25 times/h, respectively) and social kidding, social biting behaviors achieved the highest values on the post-weaning phase $(0.25 \pm 0.03$, $0.31 \pm 0.03$ times/h, respectively). On the contrary, the frequency of lying, standing, slow-moving and individual rolling were strongly decreased on the weaning day and post-weaning phase compare to pre-weaning phase, which were the least frequencies on the weaning day (Table $3, P<0.05$ ). Other 3 behavior patterns had no effect on the behavioral observations.

Numbers with different letters within each behavior are significantly different $(P<0.05)$.

\section{Behavioral observations between pre-weaning, weaning day and post-weaning phase for group $\mathrm{C}$ (8-month foals)}

The 8-month foals spent the highest frequency on the drinking,

\begin{tabular}{|c|c|c|}
\hline Categories & Behavior & Description \\
\hline \multirow{2}{*}{ Ingestion Behavior } & Feeding & Feed intake (grass, hay, force-feed) \\
\hline & Drinking & Water intake \\
\hline \multirow{2}{*}{ Excretion Behavior } & Urination & Self explanatory \\
\hline & Defecation & Self explanatory \\
\hline \multirow{4}{*}{ Movement Behavior } & Lying & All lying position \\
\hline & Standing & All degrees of wakefulness: resting, waking, indifference \\
\hline & Fast-moving & Moving forward at a gallop, trot \\
\hline & Slow-moving & Forward movement in the step \\
\hline \multirow{5}{*}{ Social Behavior } & Kicking & Aggression against social partners: kicking \\
\hline & Biting & Aggression against social partners: biting \\
\hline & Social suck & Act of social suck at the mother (or at other social partners) \\
\hline & Game & Play behavior with social partners \\
\hline & Friend & Peaceful interactions social partners: sniffing, light caressing, etc \\
\hline \multirow[t]{2}{*}{ Individual Behavior } & Individual nibbling & Nibbling of wood or wall \\
\hline & Rolling & Running game (alone) \\
\hline
\end{tabular}

Table 1: Definitions of the observed behaviors. 
Citation: Xiao H, Zhang L, Tuohut A, Shi G, Li H (2015) Effect of Weaning Age on Stress-Related Behavior in Foals (Equus Caballus) by Abrupt Group Weaning Method. J Phylogen Evolution Biol 3: 151. doi:10.4172/2329-9002.1000151

Page 3 of 6

\begin{tabular}{|c|c|c|c|}
\hline $\begin{array}{l}\text { Behavior } \\
\text { (times/h) }\end{array}$ & Pre-weaning & Weaning-day & Post-weaning \\
\hline Feeding & $6.10 \pm 0.86^{\mathrm{a}}$ & $5.5 \pm 2.83^{\mathrm{a}}$ & $4.85 \pm 0.48^{\mathrm{a}}$ \\
\hline Drinking & $0.45 \pm 0.16^{b}$ & $1.58 \pm 0.25^{a}$ & $1.02 \pm 0.14^{\mathrm{ab}}$ \\
\hline Urination & $0.03 \pm 0.03^{b}$ & $0.50 \pm 0.17^{a}$ & $0.01 \pm 0.02^{b}$ \\
\hline Defecation & $0.20 \pm 0.07^{a}$ & $0.33 \pm 0.00^{\mathrm{a}}$ & $0.10 \pm 0.03^{a}$ \\
\hline Lying & $0.27 \pm 0.04^{a}$ & $0.17 \pm 0.17^{a}$ & $0.19 \pm 0.05^{a}$ \\
\hline Standing & $17.4 \pm 2.00^{\mathrm{a}}$ & $4.59 \pm 4.59^{b}$ & $4.93 \pm 1.28^{b}$ \\
\hline Fast-moving & $0.00 \pm 0.00^{\mathrm{a}}$ & $6.34 \pm 5.17^{\mathrm{a}}$ & $7.66 \pm 1.97^{\mathrm{a}}$ \\
\hline Slow-moving & $17.29 \pm 1.99^{a}$ & $9.75 \pm 0.08^{b}$ & $12.48 \pm 0.78^{\mathrm{ab}}$ \\
\hline Social kidding & $0.06 \pm 0.06^{\mathrm{a}}$ & $0.17 \pm 0.17^{\mathrm{a}}$ & $0.21 \pm 0.05^{\mathrm{a}}$ \\
\hline Social biting & $0.06 \pm 0.06^{\mathrm{a}}$ & $0.75 \pm 0.58^{a}$ & $0.24 \pm 0.06^{\mathrm{a}}$ \\
\hline Social suck & $1.80 \pm 0.39^{a}$ & $0.40 \pm 0.07^{b}$ & $0.21 \pm 0.05^{b}$ \\
\hline Social game & $0.06 \pm 0.06^{b}$ & $0.92 \pm 0.09^{a}$ & $0.27 \pm 0.07^{b}$ \\
\hline Friend & $0.06 \pm 0.05^{b}$ & $0.83 \pm 0.50^{\mathrm{a}}$ & $0.22 \pm 0.05^{\mathrm{ab}}$ \\
\hline Individual nibbling & $0.16 \pm 0.09^{a}$ & $0.75 \pm 0.42^{\mathrm{a}}$ & $0.16 \pm 0.05^{\mathrm{a}}$ \\
\hline Individual rolling & $0.57 \pm 0.15^{\mathrm{a}}$ & $0.00 \pm 0.00^{\mathrm{b}}$ & $0.04 \pm 0.01^{b}$ \\
\hline
\end{tabular}

Table 2: Differences behavior between pre-weaning, weaning day and post-weaning phase for group $A(6-m o n t h$ foals) (Mean \pm S.E).

\begin{tabular}{|c|c|c|c|}
\hline $\begin{array}{l}\text { Behavior } \\
\text { (times/h) }\end{array}$ & Pre-weaning & Weaning-day & Post-weaning \\
\hline Feeding & $7.16 \pm 0.82^{\mathrm{a}}$ & $5.81 \pm 0.38^{\mathrm{a}}$ & $5.39 \pm 0.47^{a}$ \\
\hline Drinking & $1.07 \pm 0.13^{b}$ & $1.86 \pm 0.16^{\mathrm{a}}$ & $1.23 \pm 0.11^{\mathrm{ab}}$ \\
\hline Urination & $0.08 \pm 0.03^{b}$ & $0.34 \pm 0.05^{a}$ & $0.12 \pm 0.01^{b}$ \\
\hline Defecation & $0.30 \pm 0.04^{a}$ & $0.20 \pm 0.05^{a}$ & $0.16 \pm 0.02^{\mathrm{a}}$ \\
\hline Lying & $0.33 \pm 0.06^{a}$ & $0.09 \pm 0.05^{b}$ & $0.28 \pm 0.03^{\mathrm{ab}}$ \\
\hline Standing & $20.2 \pm 1.64^{a}$ & $9.96 \pm 0.73^{b}$ & $11.9 \pm 0.67^{b}$ \\
\hline Fast-moving & $0.00 \pm 0.00^{b}$ & $0.53 \pm 0.49^{a}$ & $0.24 \pm 0.04^{\mathrm{ab}}$ \\
\hline Slow-moving & $20.2 \pm 1.63^{a}$ & $10.88 \pm 0.69^{b}$ & $12.2 \pm 0.70^{\mathrm{b}}$ \\
\hline Social kidding & $0.00 \pm 0.00^{\mathrm{b}}$ & $0.21 \pm 0.08^{\mathrm{a}}$ & $0.25 \pm 0.03^{\mathrm{a}}$ \\
\hline Social biting & $0.00 \pm 0.00^{\mathrm{b}}$ & $0.29 \pm 0.12^{\mathrm{a}}$ & $0.31 \pm 0.03^{\mathrm{a}}$ \\
\hline Social suck & $2.56 \pm 0.36^{a}$ & $0.42 \pm 0.25^{b}$ & $0.39 \pm 0.04^{b}$ \\
\hline Social game & $0.01 \pm 0.01^{b}$ & $0.58 \pm 0.28^{a}$ & $0.33 \pm 0.04^{\mathrm{a}}$ \\
\hline Friend & $0.26 \pm 0.12^{\mathrm{a}}$ & $0.21 \pm 0.12^{\mathrm{a}}$ & $0.27 \pm 0.03^{\mathrm{a}}$ \\
\hline Individual nibbling & $0.33 \pm 0.11^{b}$ & $0.77 \pm 0.15^{\mathrm{a}}$ & $0.27 \pm 0.03^{b}$ \\
\hline Individual rolling & $1.25 \pm 0.21^{\mathrm{a}}$ & $0.03 \pm 0.03^{b}$ & $0.14 \pm 0.04^{b}$ \\
\hline
\end{tabular}

Table 3: Differences behavior between pre-weaning, weaning day and post-weaning phase for group A (7-month foals) (Mean \pm S.E).

urination, defecation, social kidding, individual nibbling behaviors on the weaning day than pre-weaning and post-weaning phases (Table 4, $\mathrm{P}<0.05)$. Whilst the lying, standing, social suck and individual rolling behaviors on the weaning day and post-weaning phase highly decrease than these behaviors on pre-weaning phases, and the frequency of these behaviors were the least on the weaning day. On the contrary, the fast-moving and social biting behaviors on the weaning day and post-weaning phase had highly difference with pre-weaning phases, these behaviors got the highest values on the post-weaning phases. The friend behavior got the highest frequency on the weaning day. There had no significance on behavioral observations for surplus 2 behaviors.

Numbers with different letters within each behavior are significantly different $(P<0.05)$.

\section{Behavioral observations between colts and fillies of different groups on the observations phases}

For Group A (6-month foals), fillies only had strongly significance on the behavior of urination, lying and social kidding than colts. Colts's fast-moving and slow-moving played significantly and more frequently than fillies (Table 5, $\mathrm{p}<0.05$ ). Gender had no difference on other 10 behaviors.
For Group B (7-month foals), fillies significantly urinated, kidded, gamed and friend than colts. Colts performed more feeding behavior $(7.02 \pm 0.49 \mathrm{~min} / \mathrm{h})$ compared to fillies $(4.79 \pm 0.50 \mathrm{~min} / \mathrm{h})$. Other 9 behavior patterns had no difference between fillies and colts (Table 5 , $\mathrm{P}<0.05)$.

For Group C (8-month foals), fillies performed more frequently than colts on the behaviors of urination, fast-moving, slow-moving, social kidding and friend, while colts had strongly significance than fillies on the behavior of feeding, lying and standing (Table 5, $\mathrm{P}<0.05$ ). There had no significance on the other 7 behavior patterns.

Behavioral response on the Gender of different groups on the observations phases (Mean \pm S.E)

\section{Discussion}

\section{Behavioral observation's methods}

The traditional and most common weaning method in horses is characterized by total and abrupt separation of mares and foals. Comparing to pre-weaning, the frequency of drinking, urination, fastmoving, aggression behaviors increased and the frequency of standing, lying and individual rolling behaviors decreased after separation for 
Citation: Xiao H, Zhang L, Tuohut A, Shi G, Li H (2015) Effect of Weaning Age on Stress-Related Behavior in Foals (Equus Caballus) by Abrupt Group Weaning Method. J Phylogen Evolution Biol 3: 151. doi:10.4172/2329-9002.1000151

Page 4 of 6

\begin{tabular}{|c|c|c|c|}
\hline $\begin{array}{l}\text { Behavior } \\
\text { (times/h) }\end{array}$ & Pre-weaning & Weaning-day & Post-weaning \\
\hline Feeding & $5.90 \pm 0.49^{a}$ & $4.13 \pm 0.30^{\mathrm{a}}$ & $4.86 \pm 0.22^{a}$ \\
\hline Drinking & $0.34 \pm 0.05^{b}$ & $1.63 \pm 0.0 .37^{a}$ & $0.88 \pm 0.10^{\mathrm{b}}$ \\
\hline Urination & $0.01 \pm 0.01^{c}$ & $0.33 \pm 0.17^{a}$ & $0.19 \pm 0.01^{b}$ \\
\hline Defecation & $0.13 \pm 0.03^{b}$ & $0.38 \pm 0.11^{\mathrm{a}}$ & $0.18 \pm 0.02^{\mathrm{b}}$ \\
\hline Lying & $0.34 \pm 0.04^{\mathrm{a}}$ & $0.13 \pm 0.13^{b}$ & $0.16 \pm 0.03^{a b}$ \\
\hline Standing & $16.5 \pm 0.89^{a}$ & $4.96 \pm 2.93^{b}$ & $5.25 \pm 0.95^{b}$ \\
\hline Fast-moving & $0.01 \pm 0.01^{\mathrm{b}}$ & $4.71 \pm 2.13^{a}$ & $5.00 \pm 0.89^{a}$ \\
\hline Slow-moving & $16.5 \pm 0.87^{a}$ & $13.4 \pm 0.84^{b}$ & $11.8 \pm 0.32^{\mathrm{b}}$ \\
\hline Social kidding & $0.00 \pm 0.00^{\mathrm{b}}$ & $1.75 \pm 0.87^{a}$ & $0.46 \pm 0.05^{b}$ \\
\hline Social biting & $0.00 \pm 0.00^{\mathrm{b}}$ & $0.29 \pm 0.08^{\mathrm{ab}}$ & $0.43 \pm 0.06^{a}$ \\
\hline Social suck & $1.20 \pm 0.18^{\mathrm{a}}$ & $0.33 \pm 0.07^{b}$ & $0.51 \pm 0.07^{b}$ \\
\hline Social game & $0.00 \pm 0.00^{\mathrm{a}}$ & $0.58 \pm 0.31^{a}$ & $0.82 \pm 0.33^{a}$ \\
\hline Friend & $0.05 \pm 0.02^{\mathrm{b}}$ & $0.50 \pm 0.01^{a}$ & $0.42 \pm 0.06^{a}$ \\
\hline Individual nibbling & $0.00 \pm 0.00^{c}$ & $0.71 \pm 0.08^{a}$ & $0.35 \pm 0.05^{b}$ \\
\hline Individual rolling & $0.84 \pm 0.15^{a}$ & $0.08 \pm 0.08^{b}$ & $0.15 \pm 0.04^{b}$ \\
\hline
\end{tabular}

Table 4: Differences behavior between pre-weaning, weaning day and post-weaning phase for group C (8-month foals) (Mean \pm S.E).

\begin{tabular}{|c|c|c|c|c|c|c|}
\hline \multirow[t]{2}{*}{ Behavior } & \multicolumn{2}{|c|}{$\begin{array}{l}\text { Group A } \\
\text { (6-month foals) }\end{array}$} & \multicolumn{2}{|c|}{$\begin{array}{l}\text { Group B } \\
\text { (7-month foals) }\end{array}$} & \multicolumn{2}{|c|}{$\begin{array}{l}\text { Group B } \\
\text { (8-month foals) }\end{array}$} \\
\hline & fillies & colts & fillies & colts & fillies & colts \\
\hline Feeding & $6.44 \pm 0.30^{a}$ & $3.99 \pm 0.63^{a}$ & $4.79 \pm 0.50^{b}$ & $7.02 \pm 0.49^{a}$ & $4.48 \pm 0.21^{b}$ & $5.63 \pm 0.31^{a}$ \\
\hline Drinking & $1.05 \pm 0.14^{a}$ & $0.80 \pm 0.19^{a}$ & $1.38 \pm 0.10^{a}$ & $1.10 \pm 0.13^{a}$ & $0.65 \pm 0.14^{a}$ & $0.97 \pm 0.10^{\mathrm{a}}$ \\
\hline Urination & $0.18 \pm 0.05^{a}$ & $0.05 \pm 0.03^{b}$ & $0.16 \pm 0.02^{a}$ & $0.09 \pm 0.02^{b}$ & $0.20 \pm 0.04^{a}$ & $0.12 \pm 0.02^{b}$ \\
\hline Defecation & $0.20 \pm 0.03^{a}$ & $0.01 \pm 0.04^{a}$ & $0.18 \pm 0.03^{a}$ & $0.20 \pm 0.02^{a}$ & $0.22 \pm 0.03^{a}$ & $0.15 \pm 0.02^{a}$ \\
\hline Lying & $0.34 \pm 0.02^{\mathrm{a}}$ & $0.08 \pm 0.04^{b}$ & $0.30 \pm 0.04^{a}$ & $0.25 \pm 0.03^{b}$ & $0.09 \pm 0.03^{b}$ & $0.31 \pm 0.03^{a}$ \\
\hline Standing & $11.12 \pm 0.77^{a}$ & $4.92 \pm 2.69^{a}$ & $12.38 \pm 0.92^{\mathrm{a}}$ & $15.35 \pm 1.32^{\mathrm{a}}$ & $3.94 \pm 1.46^{\mathrm{a}}$ & $12.12 \pm 0.70^{a}$ \\
\hline Fast-moving & $0.33 \pm 0.10^{b}$ & $10.93 \pm 0.18^{a}$ & $0.29 \pm 0.09^{b}$ & $0.11 \pm 0.03^{a}$ & $7.18 \pm 0.93^{a}$ & $0.27 \pm 0.86^{b}$ \\
\hline Slow-moving & $11.28 \pm 0.72^{a}$ & $15.64 \pm 1.28^{a}$ & $12.82 \pm 0.88^{a}$ & $15.44 \pm 1.35^{a}$ & $13.97 \pm 0.43^{a}$ & $12.23 \pm 0.69^{b}$ \\
\hline Social kidding & $0.28 \pm 0.05^{a}$ & $0.05 \pm 0.04^{b}$ & $0.24 \pm 0.03^{a}$ & $0.11 \pm 0.03^{b}$ & $0.64 \pm 0.18^{a}$ & $0.26 \pm 0.05^{b}$ \\
\hline Social biting & $0.28 \pm 0.05^{a}$ & $0.20 \pm 0.11^{a}$ & $0.29 \pm 0.04^{a}$ & $0.16 \pm 0.05^{a}$ & $0.40 \pm 0.09^{a}$ & $0.22 \pm 0.04^{a}$ \\
\hline Social suck & $0.64 \pm 0.16^{a}$ & $0.61 \pm 0.31^{a}$ & $1.08 \pm 0.30^{a}$ & $0.80 \pm 0.14^{a}$ & $0.74 \pm 0.08^{a}$ & $0.59 \pm 0.13^{a}$ \\
\hline Social game & $0.36 \pm 0.07^{a}$ & $0.18 \pm 0.10^{\mathrm{a}}$ & $0.37 \pm 0.06^{a}$ & $0.16 \pm 0.05^{b}$ & $0.92 \pm 0.45^{\mathrm{a}}$ & $0.26 \pm 0.06^{a}$ \\
\hline Friend & $0.30 \pm 0.29^{a}$ & $0.18 \pm 0.11^{a}$ & $0.38 \pm 0.06^{a}$ & $0.13 \pm 0.03^{b}$ & $0.46 \pm 0.07^{a}$ & $0.21 \pm 0.03^{b}$ \\
\hline Individual nibbling & $0.22 \pm 0.06^{\mathrm{a}}$ & $0.19 \pm 0.10^{a}$ & $0.44 \pm 0.06^{a}$ & $0.20 \pm 0.05^{b}$ & $0.37 \pm 0.07^{a}$ & $0.21 \pm 0.04^{a}$ \\
\hline Individual rolling & $0.20 \pm 0.10^{a}$ & $0.14 \pm 0.08^{a}$ & $0.30 \pm 0.13^{a}$ & $0.53 \pm 0.14^{a}$ & $0.36 \pm 0.08^{a}$ & $0.27 \pm 0.10^{a}$ \\
\hline
\end{tabular}

Table 5: Behavioral response on the Gender of different groups on the observations phases (Mean \pm S.E).

three groups (Table 2-4). These results have been described previously $[7,10,20-22,24]$. Urination, vocalizations and activity appear to be useful indicators of weaning stress in horses [20]. However vocalizations in our study could not be included as an acoustic recording of individual foals due to space and technical conditions was not possible.

For the weaning methods, different researcher used the different weaning procedure. Heleski compared the individual and group weaning, who reported the individual weanlings were lying $(\mathrm{P}<0.003)$ and aberrant behaviors $(\mathrm{P}<0.03)$ more than the groups weanlings [21]. On the contrary comparing to single stall weaned foals, those weaned into stalls as established pairs, engage in elevated levels of aggressive and standing behavior [4,25]. Whilst in our study, the social game and social friend behaviors after separation had higher frequency than these behaviors on the pre-weaning phases (Table 2-4). One possible explanation is that foals lived in group before and after weaning, they were familiar with each other and can quickly adapt to the weaning, which may minimise the occurrence of inter-foal aggression post weaning. That means it is better welfare for foal to wean with group, just as the previous report of group weaning of foals was associated with a lower incidence of behavioral indicators of stress comparing to weaning foals into isolation [4].

\section{Behavioral observations from pre-weaning to post-weaning phase}

Heleski showed that all weanlings in both treatments showed increased overall activity and decreased eating behavior on day one post-weaning compared with day seven post-weaning $(\mathrm{P}<0.01)[21]$. Locomotion was most pronounced on weaning day in foals without mares [26].

Holland [19] found that the abruptly weaned foals walked more on day one and two after weaning $(\mathrm{P}<0.0001)$ than gradually weaned foals. Abruptly weaned foals cantered more on day one $(P=0.0002)$ than gradually weaned foals. Gradually weaned foals grazed more $(\mathrm{P}=0.0002)$ than abruptly weaned foals. Sara Muhonen reported that the foals without dams spend less time resting and eating, took more time drinking, defecating and urinating and aggression on removal days than the day after removal days [8].

Similar to these results, we found that the most of behavioral reactions such as drinking, urination, lying, standing, fast-moving, slow-moving, aggression, friend, social suck, game and individual 
behaviors had been happen on the weaning day (Day 0) (Table 2-4). This increase in drinking behavior can be directly after weaning due to cessation of milk as the main nutritional source. These results implied that all foals were disturbed on removal days and the behavioral responses of weaning would be declined over time, similar results have also been reported by foals $[22,25]$ and for lambs [17,27] and calves $[5,24]$.

\section{Behavioral observations between colts and fillies}

In the present study we found that the urination and social kidding behaviors of fillies for three groups had significant frequency than colts's (Table 4). We also found that colts spent more time feeding than fillies for group B and group $\mathrm{C}$, which is in agreement with the previous reports [25], Moons found that fillies walked more $(p<0.01)$ than colts and on the post-weaning day, whilst we find the same results for the group B and group C [28].

\section{Behavioral observations between the weaning ages of 6-month, 7-month and 8-month foals}

We detected great differences in most behavioral profile between foals at different ages (Table 1-3). These results are in accordance with those reported by Tateo [29]. In our study, the 7-month and 8-month foals performed more great increase on the recording of drinking, urination, fast-moving, social kidding, social biting, individual nibbling behaviors and decreased more greatly in the frequency of lying, standing, slow-moving, individual rolling behaviors after separation when compared to pre-weaning, while for the 6-month foals just only increased the frequency of drinking, social game, friend behaviors and greatly decreased in the recording of standing, social suck, individual rolling behaviors after separation when compared to pre-weaning (Table 1-3). These could be due to lower stress response for 6-month foals. Warren [30] found that weaning foals at 6.0 months of age seems to provide little growth advantage over weaning foals at 4.5 months of age. Lansade [31] reported that 6 months of age was an optimal weaned period, when they were already relatively independent from their mothers. The possible explanation are that they have the teeth and intestinal flora to handle adult grain and forage rations in that age, they should be well-developed enough to thrive independently [32].

In our experiment, we chosen 15 behavior patterns for three different ages group, and during the observation phase 8 behavior categories had difference for group A (6-month foals), 12 behavior categories for group B (7-month foals) and 13 behavior categories group C (8-month foals). These results show that the 6-month foals are the least weaning stress than other ages and it is the optimal weaning age phase when using the abrupt and group weaning way.

\section{Conclusion}

Abrupt method is the traditional and popular weaning way, we put the foals into three groups before and after abrupt weaning, it is the better phase to wean when the foals are 6-month years old by abrupt - group weaning method in China. After removing mares, we should pay more attention to the drinking, urination, lying, standing, fast-moving, slow-moving, friend, social suck, game and individual on the weaning day. However, it requires further and more extensive quantitative studies to gain more insight into optimal weaning age and predictability in short-and long-term consequences of stress during abrupt weaning on the horse production.

\section{Acknowledgements}

We thank all the members of staff at Xinjiang Yili Zhaosu stud, and students
Z.Y.WU, K.HE etc, who assisted in managing and doing experiment the horses for this study.

\section{References}

1. Knight DA, Tyznik WJ (1985) The effect of artificial rearing on the growth of foals. J Anim Sci 60: 1-5.

2. Malinowski K, Hallquist NA, Helyar L, Sherman AR, Scanes CG (1990) Effect of different separation protocols between mares and foals on plasma cortisol and cell-mediated immune response. Journal of Equine Veterinary Science 10 363-368.

3. Myers SE, Faulkner DB, Ireland FA, Parrett DF (1999) Comparison of three weaning ages on cow-calf performance and steer carcass traits. J Anim Sci 77: $323-329$

4. Waran N, McGreevy P, Casey RA (2007) Training Methods and Horse Welfare. The Welfare of Horses 1: 151-180.

5. Haley DB, Bailey DW, Stookey JM (2005) The effects of weaning beef calves in two stages on their behavior and growth rate. J Anim Sci 83: 2205-2214.

6. Hessel EF, Reiners K, Van den Weghe HF (2006) Socializing piglets before weaning: effects on behavior of lactating sows, pre- and postweaning behavior, and performance of piglets. J Anim Sci 84: 2847-2855.

7. McCall CA, Potter GD, Kreider JL (1985) Locomotor, vocal and other behavioral responses to varying methods of weaning in foals. Appl Anim Behav Sci 14: $27-$ 35 .

8. Muhonen SLM (2003) The behaviour of foals before and after weaning in group, University of Swedish University. Master Thesis.

9. Apter RC, Householder DD (1996) Weaning and weaning management of foals: A review and some recommendations. Journal of Equine Veterinary Science 16: 428-435

10. Cockram, Imlaha P, Goddardb PJ, Harkissc GD, Warand NK (1993) The behavioral, endocrine and leucocyte response of ewes to repeated removal of lambs before the age of natural weaning. Applied Animal Behaviour Science 38: 127-142.

11. Mal ME, McCall CA, Cumminsb KA, Newlandc MC (1994) Influence of preweaning handling methods on post-weaning learning ability and manageability of foals. Applied Animal Behaviour Science 40: 187-195.

12. Church JS, Hudson RJ (1999) Comparison of the stress of abrupt and interval weaning of farmed wapiti calves (Cervus elaphus). Small Ruminant Research 32: $119-124$

13. Orgeur P, Bernard S, Naciri M, Nowak R, Schaal B, et al. (1999) Psychobiological consequences of two different weaning methods in sheep. Reprod Nutr Dev 39 231-244.

14. Hickey MC, Drennan M, Earley B (2003) The effect of abrupt weaning of suckle calves on the plasma concentrations of cortisol, catecholamines, leukocytes acute-phase proteins and in vitro interferon-gamma production. J Anim Sci 81: 2847-2855.

15. Rogers CW, Gee EK, Faram TL (2004) The effect of two different weaning procedures on the growth of pasture-reared Thoroughbred foals in New Zealand. N Z Vet J 52: 401-403.

16. Haley DB (2006) The behavioural response of cattle (Bos taurus) to articial weaning in two stages. Univ of Saskatchewaan.

17. Schichowski C, Moors E, Gauly M (2008) Effects of weaning lambs in two stages or by abrupt separation on their behavior and growth rate. J Anim Sci 86: $220-225$

18. Lynch EM, Earley B, McGee M, Doyle S (2010) Effect of abrupt weaning at housing on leukocyte distribution, functional activity of neutrophils, and acute phase protein response of beef calves. BMC Veterinary Research 6 .

19. Holland JL, Kronfeld DS, Greiwe-Crandell KM, Boyd TL, Cooper WL, et al. (1996) Weaning stress is affected by nutrition and weaning methods. Pferdeheilkunde 12: 257-260.

20. Houpt KA, Hintz HF, Butler WR (1984) A preliminary study of two methods of weaning foals. Applied Animal Behaviour Science 12: 177-181.

21. Heleski, CR Shelle AC, Nielsen BD, Zanella AJ (2002) Influence of housing on weanling horse behavior and subsequent welfare. Applied Animal Behaviour Science 78: 291-302. 
Citation: Xiao H, Zhang L, Tuohut A, Shi G, Li H (2015) Effect of Weaning Age on Stress-Related Behavior in Foals (Equus Caballus) by Abrupt Group Weaning Method. J Phylogen Evolution Biol 3: 151. doi:10.4172/2329-9002.1000151

22. Nicol CJ, Badnell WAJ, Kelland A, Wilson AD, Harris PA, et al. (2005) The effects of diet and weaning method on the behaviour of young horses. Applied Animal Behaviour Science 95: 205-221.

23. Fraser $D$ (1978) Observations on the behavioural development of suckling and early-weaned piglets during the first six weeks after birth. Animal Behaviour 26: $22-30$.

24. Loberg JM, Hernandez CE, Jensenc MB, Bergd C, Lidforsa L, et al. (2008) Weaning and separation in two steps - A way to decrease stress in dairy calves suckled by foster cows. Applied Animal Behaviour Science 111: 222-234.

25. Hoffman RM, Kronfeld DS, Holland JL, Greiwe-Crandell KM (1995) Preweaning diet and stall weaning method influences on stress response in foals. J Anim Sci 73: 2922-2930.

26. Orgeur PMNY (1998) Artificial weaning in sheep: consequences on behave.
27. Erber R, Wulf M, Rose-MeierhOfer S, Becker-Birck M, Möstl E, et al. (2012) Behavioral and physiological responses of young horses to different weaning protocols: a pilot study. Stress 15: 184-194.

28. Journal hormonal and immunopathological indicators of welfare. J Appl Anim Behav Sci 58: 87-103.

29. Moons CPH, Laughlin K, Zanella AJ (2005) Effects of short-term maternal separations on weaning stress in foals. Applied Animal Behaviour Science 91: 321-335.

30. Tateo A, De Palo P, Padalino B, Centoducati P (2009) Artificially suckled I.H.D.H. (Italian Heavy Draught Horse) foals: in vivo performances and ethograms. Ital J Animal Sci: 724-726.

31. Warren LK, Lawrence LM, Parker AL, Barnes T, Griffin AS (1998) The effect of weaning age on foal growth and radio graphic bone density. Journal of Equine Veterinary Science 18: 335-340.

32. Lansade L, Bertrand M, Boivinb X, Bouissoua MF (2004) Effects of handling at weaning on manageability and reactivity of foals. Applied Animal Behaviour Science 87: 131-149. 